\title{
SELECTING LOGISTICS PROVIDERS IN THAILAND: A SHIPPERS' PERSPECTIVE
}

\author{
Ruth Banomyong , \\ Nipawis Ritthironk, \\ Paitoon Varadejsatitwong \\ Thammasat Business School \\ Thammasat University, Thailand \\ $\&$ \\ Nucharee Supatn \\ School of Management \\ Assumption University, Thailand
}

\begin{abstract}
Competition in the export logistics service industry is very high in Thailand. The purpose of this paper is to present the findings of a survey conducted on behalf of a leading Thai logistics service provider (LSP). The objective of the research was to identify critical factors that could affect the decision making process of LSP selection. It was therefore important for the Thai LSP to understand which factors could affect shippers' decision in choosing LSP in order to maintain its dominant position.

A logistics regression model was developed to understand the factors that would impact on shippers' decision-making process when choosing logistics service providers. Based on the literature, a total of 23 factors that influence the selection process were used. It was first assumed that "price" would be one of the most significant factors to be taken into consideration by shippers but the result showed that "accuracy of documents" and "updated freight rates" was the most statistically significant factors that could contribute to a change in service providers.
\end{abstract}

Keywords: logistics service providers, decision-making, Thailand

\section{INTRODUCTION}

Freight transport has been recognised for many years as an important activity within the physical distribution function. The choice of transportation mode can greatly affect the operational costs and customer service level of a firm which, in turn, could affect the performance of the said firm. Freight forwarding is considered as a supporting business for the country's economic growth (TIFFA, 2004). Thai freight forwarders have been helping Thai import-export firms for more than 30 years, since they act as trade facilitators such as in the handling of customs procedures, consolidation services for small scale exporters and importers, negotiating with shipping lines, or other transport service providers and finally co-

* Corresponding author at: Banomyong@thammasat.net 
ordinating with all related parties. Freight forwarders have to work closely with shippers and consignees as they have to adapt themselves and provide more value-added logistics activities in order to respond effectively with the ever changing need of customers' logistics requirement. This has led freight forwarders to effectively become logistics service providers (LSPs), in particular with regards to international logistics services.

The purpose of this study was therefore to identify statistically significant factors that could affect the shipper's decision making process when selecting LSPs. An understanding of the key decision factors could help Thai LSPs in providing the sort of information and services that is considered to be critically important to their customers.

\section{SELECTING LOGISTICS SERVICE PROVIDERS}

The choice of LSPs will have a direct impact on the efficiency of international logistic channels. Each LSPs possesses different characteristics, different strengths and weaknesses. Depending on the LSP chosen (Liberatore \& Miller, 1995), the overall performance of the logistic channel will be affected. In 1992, D'Este developed a behavioural framework to represent the various stages in the decision-making process and the interaction of factors that influenced shipping managers when selecting carriers in the Ro/Ro ferry trade between Melbourne and Tasmania in Australia. The study also discovered that most respondents had developed intuitive selection techniques and found it very difficult to analyse and explain how their choices were made. Decision-makers' own perception will determine whether or not a particular LSP will be selected. The process of selecting the appropriate LSP is dependent upon a variety of service quality attributes (Evers, et al., 1996; Kent \& Parker, 1998). The service quality approach is an attempt to understand customer satisfaction from the perspective of the differences between customer perceptions and actual customer service on various attributes (Parasuraman, et al., 1985). However, the dimensions of reliability; responsiveness; assurance; empathy; tangibility and cost in the service quality approach can also be used in identifying critical factors that may affect LSP selection (Kong \& Mayo, 1993; Bienstock, et al., 1997). Figure 1 describes the decision-making model.

Figure 1: LSP selection decision-making model

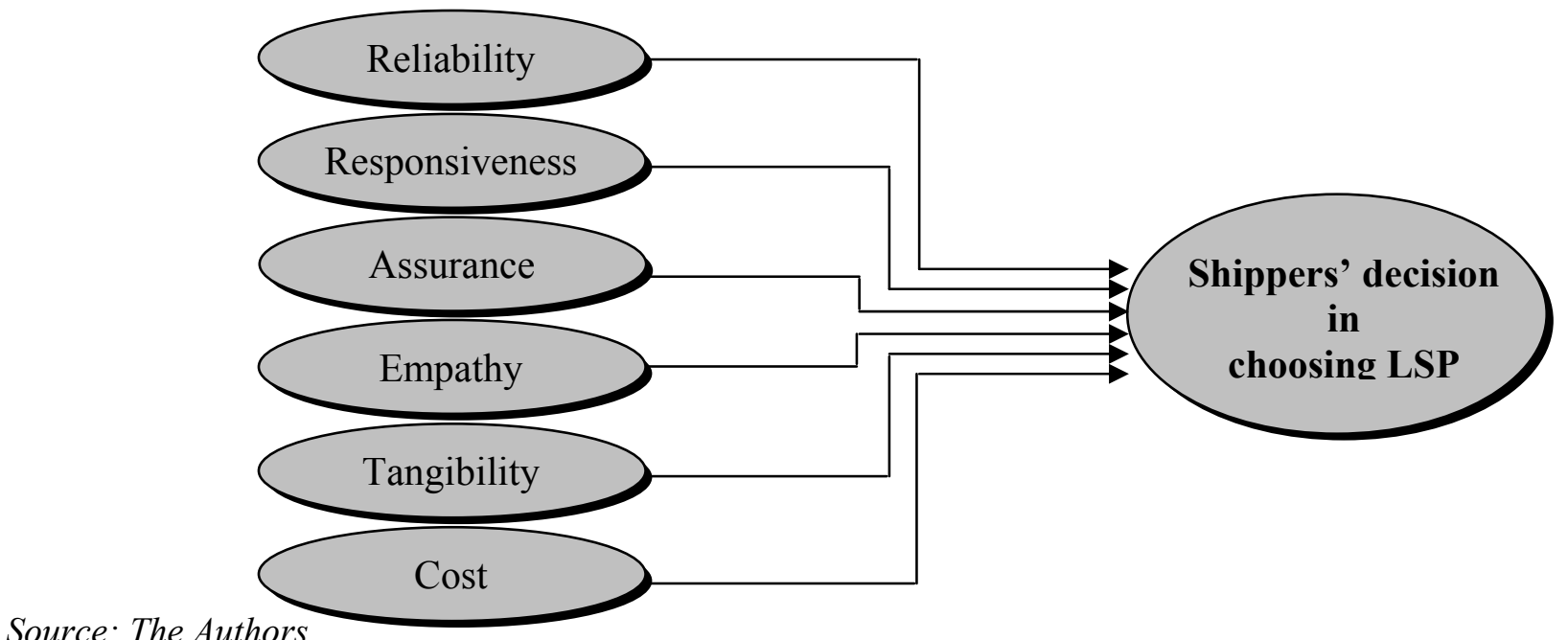




\section{METHODOLOGY}

The 6 dimensions of the service quality approach were then further elaborated as shown in table 1 hereunder.

Table 1: Factors affecting decision-making process

\begin{tabular}{|c|c|c|c|c|c|}
\hline Reliability & Responsiveness & Assurance & Empathy & Tangibility & Cost \\
\hline $\begin{array}{l}\text {-Transit time } \\
\text {-Service } \\
\text { Consistency } \\
\text {-Document } \\
\text { Accuracy }\end{array}$ & $\begin{array}{l}\text {-Responsiveness } \\
\text {-Variety of } \\
\text { Services } \\
\text {-Express Delivery } \\
\text {-Global coverage } \\
\text {-Updated rates } \\
\text {-Track and Trace } \\
\text {-Containerisation } \\
\text {-Consolidation }\end{array}$ & $\begin{array}{l}\text {-Reputation } \\
\text {-No Goods } \\
\text { Damages }\end{array}$ & $\begin{array}{l}\text {-CRM } \\
\text {-Employee } \\
\text { Courtesy }\end{array}$ & $\begin{array}{l}\text {-Location } \\
\text {-Modern } \\
\text { Equipments } \\
\text {-Own CFS } \\
\text {-E-services } \\
\text {-EDI }\end{array}$ & $\begin{array}{l}\text {-Price } \\
\text {-Discount } \\
\text {-Credit term }\end{array}$ \\
\hline
\end{tabular}

Source: The Authors

These 23 variables are derived from the literature and are believed to influence the decisionmaking process of shippers when selecting LSPs. In selecting the sample, the research sponsor decided to focus on the top three exporting industries in Thailand as these industries represent almost $50 \%$ of the value of the top ten export industries in the country. The data was collected through a questionnaire with 200 responding firms selected by the sponsor. The respondent in the targeted firm was the one who had the authority to choose LSPs. One hundred sixty seven questionnaires were returned with a response rate of $83.5 \%$. The sample included 129 firms that currently used logistics service providers when exporting while in contrast the rest had direct contacts with shipping lines. A logistic regression analysis was used to examine the relationships between these independent variables and shippers' decision-making whether to select or not select a particular LSP.

\section{FINDINGS:}

Figure 2 describes respondent characteristics and preferred freight transport mode. Out of the 167 samples, 44\% did import and export activities, $52 \%$ just export activities and $4 \%$ just import activities. $36 \%$ of shippers only used LSPs while $19 \%$ dealt exclusively with shipping lines. The rest used both LSPs and shipping lines simultaneously. Sea transport was the most popular transportation mode. Table 2 indicates that importing and exporting firms usually select both LSPs and shipping lines. The reason for those firms to use both type of service providers maybe because varied product characteristics which may require different types logistical services. $66 \%$ of pure exporting firms and around $72 \%$ of pure importing firms prefer to use only LSPs.

Figure 2: Sample characteristics categorised by type of business, and transportation mode.




Table 2: Shippers' selection of LSPs \& shipping lines

\begin{tabular}{lcccc}
\hline \hline & LSPs & Shipping Lines & $\begin{array}{c}\text { LSPs \& Shipping } \\
\text { Lines }\end{array}$ & Total \\
\hline Export & 58 & 30 & - & 88 \\
Import & 13 & 5 & - & 18 \\
Export \& Import & - & - & 61 & 61 \\
Total & 71 & 35 & 61 & 167 \\
\hline \hline
\end{tabular}

Source: The Authors

The logistic regression analysis revealed a significant relationship between the decision influencing factors and shippers' decision in choosing LSPs $\left(\chi^{2}=79.204, p=.006\right)$. The Betacoefficient presented in table 3 indicates the level of relationship between each decision influencing factor and shippers' decision in choosing LSPs.

Table 3: The Logistic Regression Analysis of the Decision Influencing Factors and shippers' decision in choosing LSP

\begin{tabular}{lc}
\hline \multicolumn{1}{c}{ Shippers' decision influencing factors } & $\boldsymbol{\beta}$-Coefficient \\
\hline \hline Location & -.360 \\
Express Delivery Service & $-1.072^{*}$ \\
Transit Time & .289 \\
Own CFS & .252 \\
Price & -.201 \\
No damaged goods while in transit & .112 \\
Customer Relationship Management $(\mathrm{CRM})$ & -.722 \\
Responsiveness of the Service & -.137 \\
Consistency of the Service & .693 \\
World-wide Service & -.449 \\
Offering of Updated freight rates & $.834^{* *}$ \\
Modern Equipments & .637 \\
Own Overseas Network & -.040 \\
Unitization/Containerization & .105 \\
E-commerce Service Offering & -.101 \\
EDI & $.579 *$ \\
Accuracy of Documents & $.936^{* *}$ \\
Variety of Services & -.536 \\
Firm's Reputation & .274 \\
Discount Offering & -.053 \\
Credit Term & -.115 \\
Consolidation & $-.650^{*}$ \\
Constant & -.630 \\
\hline Omnnibus Tests of Model Coefficients: & \\
chi-square = 79.204 Sig $=.006$ & \\
\hline \hline Remarks: $* x \leq 0.10, * * p \leq 0.05$ &
\end{tabular}

The updated freight rates offering and accuracy of documents are significant statistically in relation to shippers' decision in choosing LSP ( $p=.036$ and .015 respectively). The greater the $\beta$-coefficient of the accuracy of the documents indicated its higher impact on shippers' decision than that of the updated freight rates offering. In addition, the express delivery service, EDI, and consolidation were found to be statistically significant but only at $90 \%$ confidence interval in relation to shippers' decision in choosing LSP with levels of 0.061 , 0.074 , and 0.056 respectively. 


\section{DISCUSSION}

The major finding was that the most important factors influencing shippers to select a LSP in Thailand were the accuracy of documents and offering of updated freight rates. The accuracy of documents was important since those documents are used as formal evidences especially in the international payment of goods procedure. Any errors or discrepancies may cause delay and other charges such as the fee for $\mathrm{L} / \mathrm{C}$ correction and so on. Moreover, documentation accuracy will also help in the smooth flow of their cargo. Updated freight rates are important to shippers and consignees to calculate the cost of delivering or receiving freight. Improving these two high impact factors should provide huge benefits for Thai LSPs. Since these two factors are internal factors, they can be easily controlled by LSP's management.

The next important decision-making factors were the express delivery service, the offering of Electronic Data Interchange (EDI), modern equipments, consistency of the service, and consolidation respectively. Besides, another factor that LSPs should be concern with was price of service, since the result indicated a negative relationship between price and shippers' decision in choosing LSP. Even though the relationship is not statistically significant but the negative relationship is interesting. The lower the service price, the more likely customers will be satisfied. Another area of concern on price may be derived from other business factors such as the impact of INCOTERM usage.

In addition, other decision influencing factors which were not statistically significant can still affect shippers' decision-making process in the selection of LSPs. Some of the not statistically factors could be explained as follows: 1) shippers perceived some factors as standard logistical service that any LSP must have such as owned CFS, provision of credit term to customers, having their own overseas network, responding to customer needs, and no damaged goods in transit. It is possible that respondents did not pay attention to these factors. 2) Some factors were difficult to differentiate. For example, most shippers perceived that transit time is dependent on the shipping schedule, not under the control of LSPs, and 3) some shippers had an insufficient understanding of some of the factors asked such as customer relationship management (CRM) and so on.

\section{REFERENCES}

Bienstock, C.C., Mentzer, J. and Bird, M.M. (1997), "Measuring Physical Distribution

Service Quality", Journal of the Academy of Marketing Science, 25 (1), 31-44.

D'Este, G.M. (1992), "Carrier selection in a RO/RO ferry trade Part. 2 Conceptual framework for the decision process", Maritime Policy \& Management, 19 (2), 127-138.

Evers, P.T., Harper, D.V., Needham, P.M. (1996) "The Determinants of Shipper Perceptions of Modes," Transportation Journal. 36 (2), 13-25.

Kent, J.L. \& Parker, S.R. (1998) "International Containership Carrier Selection Criteria: Shippers/Carriers differences", International Journal of Physical Distribution and Logistics Management, 29 (6), 398-408.

Kong, R. and Mayo, M. (1993), "Measuring Service Quality in the Business-to-Business

Context", Journal of Business \& Industrial Marketing, 8 (2), 5-15.

Liberatore, M.J. \& Miller, T. (1995) "A decision support approach for transport carrier and mode selection", Journal of Business Logistics, 16 (2), 85-115.

Parasuraman...? 
TIFFA (2004), Thailand Freight Forwarding Handbook 2004, Cosmic Publication, Bangkok. 